\title{
Brasil, balanço econômico, sucessos e limites
}

\author{
PIERRE SALAMA ${ }^{I}$
}

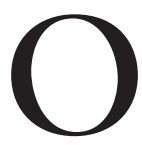

PRESIDENTE Lula deixa o poder com uma grande aprovação, tanto pela imprensa internacional quanto pelos cidadãos do seu país. De cada cinco brasileiros, quatro apoiam sua política. Ele entra na história pela porta principal, como Vargas ou Kubitschek. A popularidade do presidente ultrapassa de longe a do seu partido, o PT, e fala-se com frequência de lulismo, sublinhando assim a parte pessoal do presidente no seu sucesso.

Seria errôneo, porém, explicar a grande popularidade do presidente que sai apenas por seu carisma junto às camadas mais deserdadas da população. Esse carisma é inegável, mas outros fatores intervêm: a melhora da situação social num país que sofre com suas desigualdades, sobretudo os mais desfavorecidos, e a melhora da situação econômica num ambiente internacional favorável, com o aparecimento da China como novo parceiro comercial.

Esquematizando, poder-se-ia dizer que o primeiro governo do presidente Lula saneou as bases macroeconômicas à custa de um déficit social considerável e de um risco de marginalizar a economia na arena mundial. O segundo governo foi mais "desenvolvimentista", 2 voltando a dar ao Estado um peso que ele perdeu desde a hiperinflação (1994), conservando ao mesmo tempo numerosos traços tomados do liberalismo (taxas de juros elevadas, apreciação da moeda, poucos investimentos públicos ainda que em crescimento, moderada reforma fiscal).

As marcas liberais e intervencionistas estão presentes nas políticas conduzidas durante os dois mandatos, mas no primeiro o liberalismo prevalece; no segundo, o intervencionismo tende a se afirmar. A primeira parte deste artigo discutirá a vulnerabilidade do Brasil resultante da abertura maior do país à economia mundial e mostrará que, se a vulnerabilidade externa parece menos elevada, a fragilidade aos choques financeiros externos permanece grande. A segunda parte se concentrará na aposta do mercado interno feita pelo governo e mostrará que essa aposta, confirmada pelas políticas anticíclicas decididas desde o início da crise, explica ao mesmo tempo a brevidade desta última e a forte retomada.

\section{Mais abertura, menos vulnerabilidade externa?}

Três pontos serão aqui sublinhados e discutidos: os efeitos imediatos produzidos pelas políticas monetárias e orçamentárias ortodoxas, o aumento das reservas internacionais e a redução da vulnerabilidade externa. 
1. A perspectiva da chegada de Lula ao poder desencadeou uma saída maciça de capitais, uma depreciação pronunciada da moeda nacional em relação ao dólar, um aumento muito forte da taxa de juros nos empréstimos internacionais do Brasil e um recrudescimento da inflação. A primeira tarefa à qual o governo se lançou, logo ao entrar em função em janeiro de 2003, foi tranquilizar os mercados financeiros internacionais e reduzir assim o custo dos empréstimos internacionais. $\mathrm{O}$ governo decidiu também aumentar bastante o superávit primário, ${ }^{3}$ para além das recomendações do Fundo Monetário Internacional (FMI), e elevar consideravelmente as taxas de juros reais ( $11,9 \%$ em 2003 contra 5,1\% em 2002 $)$ e mantê-las elevadas a fim de reduzir de forma durável a taxa de inflação.

Os mercados financeiros internacionais se surpreenderam favoravelmente com as medidas adotadas: os capitais voltaram a afluir e a moeda foi fortemente reapreciada (valorização que prosseguirá até a crise de 2008). A taxa de inflação baixou pela metade ( $5,7 \%$ em 2004$)$, o saldo positivo da balança comercial aumentou e o do balanço das contas correntes ${ }^{5}$ tornou-se positivo a partir de 2003. As reservas internacionais do país cresceram, a dívida pública externa diminuiu. Desse ponto de vista, as medidas liberais adotadas foram eficazes: elas sufocaram o risco inflacionário e permitiram o retorno dos capitais.

No passivo, porém, as políticas monetárias e orçamentárias tiveram um custo social imediato importante. A taxa de crescimento do PIB caiu e passou de $2,7 \%$ em 2002 para $1,1 \%$ em $2003 .{ }^{6}$ A taxa de investimento, modesta $(16,4 \%$ do PIB em 2002), baixou em 1,1 ponto. A taxa de desemprego aumentou e passou de $11,8 \%$ em janeiro de 2003 a 13,2\% em novembro do mesmo ano, para depois diminuir de novo. A massa salarial sofreu uma forte contração (-12,3\%) em 2003, apesar de um aumento do salário mínimo em termos reais.

Indicadores macroeconômicos

\begin{tabular}{|c|c|c|c|c|c|c|c|c|}
\hline Em \% & 2003 & 2004 & 2005 & 2006 & 2007 & 2008 & 2009 & $2010^{*}$ \\
\hline Taxa de crescimento do PIB & 1,2 & 5,7 & 3,2 & 4 & 6,1 & 5,1 & 0 & 5,5 \\
\hline FBCF /PIB & 15,3 & 16,1 & 15,9 & 16,4 & 17,4 & 18,7 & 18,7 & Nc \\
\hline $\begin{array}{l}\text { Taxa de crescimento do salário } \\
\text { mínimo em termos reais }\end{array}$ & 4 & 3,3 & 7,6 & 12,1 & 5,6 & 4,8 & 6,8 & 5.1 \\
\hline $\begin{array}{l}\text { Taxa de inflação, IPCA } \\
\text { (bens de consumo) }\end{array}$ & 9,3 & 7,6 & 5,7 & 3,1 & 4,5 & 5,9 & 4,3 & Nc \\
\hline Taxa de juro real & 11,9 & 7,5 & 11,9 & 11 & 6,8 & 5,9 & Nc & Nc \\
\hline $\begin{array}{l}\text { Saldos do balanço das contas } \\
\text { correntes em \% do PIB }\end{array}$ & 0,8 & 1,8 & 1,8 & 1,5 & 0,26 & $-1,96$ & $-1,57$ & $-2,51$ \\
\hline
\end{tabular}

Fonte: Relatório do Banco Central do Brasil (2009) e IBGE; * previsões.

2. A necessidade de financiamento externo (soma do déficit do balanço das contas correntes e da amortização da dívida) baixa consideravelmente até 2005 . Passa de 64,3 bilhões de dólares no terceiro trimestre de 2001 para 15,6 bilhões no segundo trimestre de 2005 . A seguir volta a aumentar consideravelmente. 


\section{A evolução contrastada da necessidade de financiamento externo}

A evolução da necessidade de financiamento se explica especialmente por dois fatores: o saldo da balança comercial tornado positivo e a redução do serviço da dívida (juros e amortização) consecutivo à redução da dívida pública externa.

O saldo positivo da balança comercial aumenta no período e atinge, em 2006, 46,5 bilhões de dólares, diminuindo em 2007 para 40 bilhões e caindo fortemente em 2008 para 24 bilhões, por causa da crise internacional. Até 2007, a evolução favorável da balança comercial compensa as saídas líquidas de capital relacionadas a diversos componentes das contas correntes (dividendos, juros ${ }^{7}$ etc.), e o saldo do balanço das contas correntes é positivo até setembro de 2007, para depois cair profundamente com a crise $(-35,6$ bilhões de dólares), reerguer-se de novo e tornar a cair em 2010 , situando-se em torno de -50 bilhões de dólares em 2010 segundo as previsões.

A dívida externa pública continua a aumentar durante o primeiro semestre de 2003, estabiliza-se a seguir e depois inicia uma queda pronunciada a partir do final de 2005, e com ela o serviço da dívida (juros e amortização do principal), enquanto a dívida externa privada cresce. A dívida externa pública líquida baixa ainda mais fortemente, a ponto de se tornar negativa a partir de junho de 2006, graças ao aumento das reservas internacionais que, aplicadas, colocam o Brasil na posição de credor internacional (ver o Quadro seguinte).

O conjunto dessas evoluções explica a evolução contrastada da necessidade de financiamento: uma forte baixa seguida de uma alta considerável. $\mathrm{O}$ serviço da dívida externa em porcentagem das exportações diminui: passa de $80 \%$ no quarto trimestre de 2002 para $20 \%$ no segundo trimestre de 2009 .

A capacidade de financiamento, alimentada pelos investimentos estrangeiros, continua a aumentar significativamente, e com eles as reservas. Os investimentos em carteira (ações, títulos e obrigações) crescem, passando de 5,3 bilhões de dólares em 2003 a 9 bilhões em 2006, para cair acentuadamente para $-4,7$ bilhões em 2009 com a crise, as saídas sendo superiores às entradas. ${ }^{8}$ O investimento estrangeiro direto bruto aumenta consideravelmente e se eleva em média a 19 bilhões de dólares por ano entre 2000 e 2005. Atinge 45 bilhões de dólares em 2008, depois cai, com a crise, para 26 bilhões, devendo se elevar a 37 bilhões de dólares em 2010, segundo as previsões. Como a capacidade de financiamento ultrapassa as necessidades, as reservas aumentam bastante. Essas, aplicadas no estrangeiro, permitem que o Brasil se torne um país credor líquido (ver o Quadro).

\section{Brasil, país credor?}

A diminuição da dívida pública externa líquida, que transforma o Brasil em país credor e não mais devedor, se explica pela aplicação das reservas 
que vinham crescendo muito. Essas são aplicadas no exterior e constituem, portanto, um crédito. Mas elas podem se revelar em parte artificiais. De fato, o aumento das reservas provém do saldo positivo da balança comercial, do balanço das contas correntes e das entradas líquidas de capitais. Esses capitais são de diversas naturezas: títulos de curto prazo, obrigações, ações, investimentos estrangeiros diretos, créditos. Os títulos, as obrigações e as ações são muito voláteis. Entram e podem sair ao sabor da especulação, da busca de liquidez por parte dos investidores internacionais. Não é o caso dos investimentos estrangeiros diretos, cujo custo de saída acarreta perdas irrecuperáveis significativamente grandes. No total, uma parte das entradas de capitais e dos lucros é suscetível de sair, diminuindo assim as reservas. Eis por que convém analisar a estrutura das reservas para avaliar a vulnerabilidade dos créditos do Brasil ligados às suas aplicações. Se decompusermos as entradas de capitais no Brasil, segundo dados do Banco Central, a participação dos investimentos diretos foi de $38 \%$ em 2009, a dos investimentos em carteira, 46\%, e a dos "não classificados", 16\%. Portanto, a "fragilidade" das reservas é relativamente alta, ao contrário do que se observa na China (saldo positivo importante da balança comercial). Apesar dessas observações, a passagem da posição do Brasil de grande devedor líquido para credor líquido é um mérito do governo Lula e reforça a posição financeira do país no cenário internacional.

3. A vulnerabilidade externa do Brasil diminuiu, mas não pôde impedir o contágio da crise financeira em 2008 e em 2009, contrariamente aos que prognosticavam uma separação das conjunturas entre os países desenvolvidos e o Brasil.9

Os indicadores de vulnerabilidade externa levam em conta diferentes linhas do balanço de pagamentos. Três indicadores são em geral privilegiados: o primeiro é um indicador de fluxo que busca medir a necessidade de financiamento externo; o segundo diz respeito às reservas; e o terceiro estabelece uma relação entre o passivo externo e seus componentes, de um lado, e o PIB, de outro.

$\mathrm{O}$ primeiro indicador considera a necessidade de financiamento externo relacionada ao PIB. Esse é calculado por uma relação em que o saldo do balanço das contas correntes, mais a amortização da dívida externa, está no numerador, e o PIB no denominador. No caso do Brasil, no período de 1998-2002, ele foi em média de $9 \%$ do PIB. No período de 2006-2007, passou para 3,7\% do PIB em média. A baixa desse indicador significa que a vulnerabilidade externa do Brasil é menos elevada que no passado.

O segundo indicador está centrado nas reservas. Ele se decompõe em quatro subindicadores. As reservas são expressas em porcentagem do PIB, das importações, da dívida externa bruta e, enfim, do serviço dessa dívida. O valor das reservas em relação ao PIB era de 5,28\% em 1998 e atingiu 13,73\% em 2007. O valor das reservas sobre as importações passou de 0,70 a 1,50 entre as mesmas 
datas. A relação das reservas sobre a dívida bruta (excluídos os empréstimos entre empresas) passou de 0,20 a 0,93 no mesmo período. Enfim, o valor das reservas em relação ao serviço da dívida conheceu uma evolução semelhante, passando nesse período de 0,99 a 3,50, e atingiu o valor 5 em junho de 2008, às vésperas da crise internacional. A relação reservas sobre dívida situava-se em 64,6 em 2002, elevou-se para 289 em 2007 e atingiu 326 em junho de 2008. Todos os componentes desse indicador mostram uma nítida diminuição da vulnerabilidade externa e confirmam o diagnóstico estabelecido com o primeiro indicador.

Um terceiro indicador pode ser construído a partir do passivo externo relacionado ao PIB. Esse indicador passa de 67,2\% para 71,5\% entre 2001 e 2007. Segundo esse indicador, a vulnerabilidade teria aumentado.

O passivo externo é composto pelos investimentos diretos, investimentos em carteira, dívida externa bruta - sem os empréstimos entre empresas - e outros passivos. Como mostra o quadro a seguir, a participação dos investimentos diretos no passivo externo passa, entre 2001 e 2007 , de $32,8 \%$ para $35 \%$, a da dívida externa bruta, de $56,4 \%$ a $20,6 \%$, e a dos investimentos em carteira, mais voláteis que os investimentos estrangeiros diretos, de $9,9 \%$ a $38,8 \%$, sendo negligenciável a dos outros passivos. Portanto, a estrutura do passivo externo mostra em 2007 uma vulnerabilidade mais elevada. A participação maior dos investimentos em carteira e da dívida externa, composta em grande parte por títulos internacionais renováveis, está assim provavelmente na origem da forte sensibilidade aos choques financeiros internacionais que se manifestou em 2008.

\begin{tabular}{l|l|c}
\hline & 2001 & 2007 \\
\hline $\begin{array}{l}\text { Passivo externo bruto } \\
\text { em \% do PIB }\end{array}$ & $67,2 \%$ & $71,5 \%$ \\
\hline
\end{tabular}

Decomposição do passivo externo bruto, 2001 e 2007

\begin{tabular}{l|c|c}
\hline Investimentos diretos estrangeiros & $32,8 \%$ & $35 \%$ \\
\hline Investimentos em carteiras & $9,9 \%$ & $38,8 \%$ \\
\hline Dívida externa bruta & $56,4 \%$ & $20,6 \%$ \\
\hline Outros passivos & $0,9 \%$ & $5,6 \%$ \\
\hline
\end{tabular}

Menos vulnerabilidade externa aparente e mais fragilidade real aos choques externos: é nesse contexto que pode ser avaliada a aposta de dinamizar o mercado interno e o crescimento sob a exigência de uma melhora da inserção internacional do país. Essa aposta não está ganha, embora progressos tenham sido realizados. É o que vamos mostrar a seguir.

\section{Um mercado interno mais dinâmico,} mas uma inserção internacional problemática

Por um lado, a política monetária e orçamentária é mantida. Por outro, o 
Estado retoma timidamente uma política industrial, multiplica as taxas de juros preferenciais no agronegócio, na habitação, na indústria, sustenta a demanda ao aumentar sensivelmente o salário mínimo e o número de beneficiários do "Bolsa família”, e aumenta os gastos públicos.

A porcentagem de pobres diminui e o número de bilionários aumenta. ${ }^{10} \mathrm{O}$ salário real cresce, as pensões aos aposentados são mais generosas, a distribuição dos rendimentos é menos desigual, os empregos informais, ainda muito numerosos, perdem sua importância relativa... O Brasil se torna, segundo a Unctad, o quarto país preferido das quatrocentas maiores empresas mundiais e, segundo Meryl Lynch, é considerado a segunda destinação mais segura no mundo. Enquanto em mais de um país da América Latina os conflitos entre indústria e agronegócio, entre indústria e finanças, entre empregadores e assalariados, entre ricos e pobres ficam mais agudos, no Brasil eles parecem atenuados, cada um parecendo "encontrar seu proveito", com exceção, provavelmente, de uma parte das camadas médias sobre as quais pesa mais o esforço fiscal.

A elevação dos salários e dos gastos sociais do Estado ${ }^{11}$ estimula o crescimento e confere ao mercado interno um papel mais importante. Contrariamente a alguns prognósticos, a indústria não declina. São esses dois pontos que abordaremos agora.

1 Um mercado interno mais dinâmico e uma sensível vedução da pobreza

a) Contrariamente à opinião comum, as transferências sociais pouco interferiram na evolução das desigualdades na América Latina e no Brasil até 2008. Os trabalhos da Organização para a Cooperação e o Desenvolvimento Econômico (OCDE, 2008), e de Goni et al. (2008) $)^{12}$ mostram claramente a influência muito fraca das transferências sobre o nível de concentração de renda, medido pelo coeficiente de Gini. ${ }^{13}$ Segundo Goni et al. (2008), a comparação entre a renda bruta (incluindo as transferências sociais) e a renda de mercado (market income) revela que o impacto dessas transferências sobre a concentração de renda é elevado na Europa dos 15 ( $-0,10$ ponto em média), mas muito fraco no Brasil (-0,02 ponto). Se considerarmos a renda disponível (transferências e impostos diretos) e a renda bruta (transferências), observamos que o impacto dos impostos sobre a redução das desigualdades é bem maior na Europa (-0,5 ponto) do que no Brasil, onde ele é nulo ou mesmo ligeiramente negativo. A fraqueza das transferências não compensa os efeitos particularmente regressivos do sistema fiscal brasileiro. ${ }^{14}$

Entre 1997 e 2006, o coeficiente de Gini dos rendimentos de trabalho passou de 0,57 a 0,53, segundo a Pesquisa Nacional por Amostra de Domicílios (Pnad). A redução das desigualdades é importante. E ela se explica essencialmente por um crescimento mais sustentado por ocasião do segundo mandato em relação ao primeiro (excetuado o ano de 2009) e pela política adotada pelo governo no que se refere ao salário mínimo.

$\mathrm{O}$ crescimento não é neutro quanto à distribuição dos rendimentos. Ele 
gera uma distribuição de renda mais ou menos desigual conforme a natureza dos empregos criados (qualificados, não qualificados), conforme os setores (industrial, financeiro, serviços, agrícola) nos quais se apoia. ${ }^{15}$ Entre 2002 e 2008, o crescimento produziu assim menos desigualdades na maior parte dos países da América Latina e, em particular, no Brasil. ${ }^{16}$ A redução das desigualdades no Brasil se explica especialmente pela melhora das condições de trabalho (emprego, salário). Sobretudo graças ao aumento do salário mínimo ${ }^{17}$ e à relativa redução dos empregos informais, a melhora da renda disponível do trabalho foi maior para os baixos rendimentos do que para os altos rendimentos. A relação entre rendimentos do trabalho principal dos $5 \%$ da população mais rica e dos $50 \%$ da população mais pobre passou de 14,3 em 1993 para 14,1 em 2003, e para 13,5 em 2008. E, entre os $5 \%$ mais ricos e os $25 \%$ mais pobres, evoluiu de 23,6 para 21,6 , e depois para 18,6 nas mesmas datas (ver Dedecca, 2010, p.16). A discrepância entre os salários diminui e a demanda por bens de consumo não duráveis se mantém. $\mathrm{O}$ aumento do crédito ao consumo, de uma maneira geral, e as facilidades de crédito para a compra de moradia e de bens duráveis, em particular, estimulam a demanda desses bens. No conjunto, a elevação do salário mínimo, acompanhada por aumentos menos elevados do salário médio e pela oferta maior de crédito, confere ao mercado interno um novo dinamismo. A contribuição ao crescimento do consumo pelas famílias é elevada e explica 80\% do crescimento do PIB em 2005 e em 2008 (cf. Paula, 2010), e sobretudo está na origem de uma aceleração do crescimento.

b) Uma redução sensível da pobreza ocorreu, apesar das transferências sociais ainda modestas.

A dimensão da pobreza do Brasil era avaliada em $35 \%$ da população em 1999. Ela declinou nitidamente a seguir: $26,9 \%$ em $2006,25,1 \%$ em 2007 , segundo a Pnad. Assim, a redução é incontestável e ocorreu sobretudo durante a presidência de Lula.

A evolução da pobreza depende de três fatores: o nível das desigualdades, sua evolução e, enfim, o crescimento da economia. Em primeiro lugar, o nível das desigualdades: quanto mais elevado ele for, mais difícil se torna reduzir a pobreza. Ora, o Brasil é um dos países de maior desigualdade no mundo. Se nos limitarmos apenas aos rendimentos de trabalho, o coeficiente de Gini (1) era de 0,53 no Brasil em 2006, enquanto se situava em torno de 0,30 na Coreia do Sul. O nível das desigualdades constitui, portanto, um fator desfavorável que torna mais difícil a redução da pobreza. O segundo fator é a evolução das desigualdades: quanto mais essas diminuem, tanto mais a pobreza recua, se o resto permanecer igual. A redução das desigualdades, portanto, atua em favor da redução do nível de pobreza. O terceiro fator é o crescimento da economia: quanto mais elevado for seu ritmo, maior será a redução da pobreza, também se o resto permanecer igual. E o Brasil de Lula de fato se beneficiou, pelo menos até 2008, de um crescimento superior e menos volátil do que durante os anos 1990. Esses dois últimos fatores estão na origem de uma sensível redução da pobreza, embora ainda haja um nível de desigualdades elevado. 
A redução das desigualdades é o produto de uma melhora das condições de trabalho, tanto em termos de empregos quanto de salários, e de um aumento sensível do salário mínimo no período. O efeito das transferências sociais sobre as desigualdades, e portanto sobre o nível da pobreza, é modesto. Segundo Sônia Rocha, ${ }^{18}$ os programas sociais prioritários (ver Quadro a seguir) reduziram apenas em $6,4 \%$ o número de pobres no Brasil, mas a situação desses melhorou. A profundidade da pobreza diminuiu.

\section{Programas sociais}

Existem no Brasil dois principais instrumentos de distribuição de renda aos pobres. Um é o Bolsa família, o outro contempla pessoas idosas desfavorecidas. A esses dois programas prioritários pode-se acrescentar o pagamento de um salário mínimo aos camponeses idosos e pobres.

O Bolsa família adquiriu uma notoriedade internacional. Ele abrange doze milhões de lares, ou seja, cerca de uma pessoa em cada quatro da população. Ao chegar ao poder em 2003, o governo Lula ampliou a aplicação desse programa e simplificou seus procedimentos. São beneficiárias as famílias cuja renda per capita é inferior a 60 reais por mês (cerca de 30 dólares). Elas recebem então 60 reais, aos quais se acrescentam 10 reais por criança de menos de quinze anos para os três primeiros filhos. As famílias que ganham entre $61 \mathrm{e}$ 120 reais só recebem alocações se tiverem filhos. No total, os gastos envolvidos no Bolsa família não ultrapassaram $0,4 \%$ do PIB em 2008, ou seja, doze a quinze vezes menos do que as somas destinadas ao serviço da dívida interna.

O outro mecanismo de redistribuição, menos conhecido, tem como alvo pessoas pobres com mais de 65 anos e rendimento inferior a um quarto do salário mínimo, assegurando-lhes uma aposentadoria igual a um salário mínimo (510 reais em $1^{\circ}$ de janeiro de 2010), ou seja, bem mais do que o benefício do Bolsa família. Embora destinado a um número bem menor de pessoas, o montante destinado a esse programa é da mesma ordem que o do Bolsa família. Ao contrário deste último, seu mecanismo de distribuição está inscrito na Constituição brasileira.

A decisão de beneficiar camponeses pobres e idosos com uma aposentadoria equivalente a um salário mínimo deve contribuir para uma diminuição importante do nível de pobreza nos campos. Essa medida, bem como a precedente, é anterior aos dois mandatos de Lula.

\section{Uma inserção internacional problemática}

Poder-se-ia pensar que a apreciação da moeda enfraqueceria o tecido industrial, com áreas inteiras ficando ameaçadas pelas importações. Não foi o que aconteceu. Mais precisamente, segmentos de linhas de produção foram substituídos por importações, mas no conjunto o setor industrial se manteve. No entanto, a capacidade de desenvolver e exportar produtos de alta e média tecnologias 
(com exceção da aeronáutica) é limitada e a taxa de investimento permanece num nível bastante baixo.

Utilizando as taxas de câmbio de paridade de poder de compra, observase que a indústria brasileira não está atrasada em relação à indústria mundial. A taxa de crescimento anual média da indústria brasileira foi mais rápida, de 2004 a 2010, que a dos países avançados, $3,4 \%$ comparado a $0,7 \%$, mas foi inferior à da Ásia (11,8\%), segundo o Banco Santander (20 de maio de 2010). No entanto, o setor industrial mostra-se menos competitivo e suas exportações padecem com isso. Três razões explicam essa situação: a apreciação da moeda, a insuficiência dos gastos de pesquisa e de desenvolvimento, enfim uma política industrial ainda tímida, apesar dos progressos recentes.

A apreciação da taxa de câmbio torna mais difíceis as exportações, exceto as das matérias-primas cujos preços são fixados em divisas, e somente uma maior competitividade pode compensar essa desvantagem. Sem considerar as matériasprimas, as exportações industriais aumentam, mas seu ritmo é ainda moderado se comparado ao das economias asiáticas. Em contrapartida, a apreciação da moeda nacional e a redução maciça dos direitos alfandegários facilitam as importações. O saldo positivo da balança comercial dos produtos da indústria da transformação baixa a partir de 2005 e se torna negativo a partir do primeiro trimestre de 2008, alguns meses antes da crise internacional. O saldo da balança comercial em geral permanece positivo, sobretudo graças à elevação das exportações de matérias-primas que passam de 6,13 bilhões de dólares, entre o terceiro trimestre de 2002 e o terceiro trimestre de 2003 , para 26 bilhões de dólares, entre o terceiro trimestre de 2008 e o terceiro trimestre de 2009, traduzindo assim uma forte primarização das exportações e da atividade econômica (cf. Instituto de Estudos para o Desenvolvimento Industrial (Iedi), a partir de dados do Banco Central do Brasil), em razão da subida dos preços das matérias-primas e das novas demandas (essencialmente asiáticas).

Por sua vez, o valor agregado das exportações diminui. É o que revelam os estudos do Iedi (22 de março de 2007). Alguns insumos importados são mais competitivos que os produzidos localmente. A baixa competitividade desses tem duas causas: a apreciação da moeda nacional e a fraqueza do esforço em pesquisa de desenvolvimento. É o que explica a importância das importações dos bens de alta e média-alta tecnologias. Junte-se a isso uma capacidade de produção insuficiente desses bens, embora a produção aumente num ritmo elevado.

A produção dos bens de alta e média-alta tecnologias cresce mais rápido que a média da indústria de transformação, e bem mais rapidamente que a produção de baixa e média-baixa tecnologias, como mostra o quadro a seguir.

A taxa de crescimento da produção dos bens de média-alta tecnologia é a mais elevada no período considerado, seguida pela dos bens de alta tecnologia. Nos bens de alta tecnologia, o setor aeronáutico vê sua produção quadruplicar, e o de material de escritório e informática um pouco mais que triplicar entre 2002 
e 2008. No setor dos bens de média-alta tecnologia, a produção automobilística teve um aumento de 36\% em 2008 em relação a 2002 (ver Carta Iedi, n.364, jun. 2009) e em 2010 deve ultrapassar a da França.

Produção segundo a intensidade tecnológica na indústria de transformação

\begin{tabular}{l|c|l|c}
\hline \multicolumn{1}{c|}{ Base 100 em 2002 } & $\begin{array}{c}\text { Out. 2002 / } \\
\text { mar. 2003 }\end{array}$ & $\begin{array}{c}\text { Out. 2007 / } \\
\text { mar. 2008 }\end{array}$ & $\begin{array}{c}\text { Out. 2008 / } \\
\text { mar. 2009 }\end{array}$ \\
\hline Bens de alta tecnologia & 91,3 & 139,5 & 139,8 \\
\hline Bens de média-alta tecnologia & 101,6 & 148,1 & 119,8 \\
\hline Bens de média-baixa tecnologia & 98,4 & 111,9 & 99,4 \\
\hline Bens de baixa tecnologia & 98 & 107 & 102,8 \\
\hline Indústria de transformação & 98,5 & 122,4 & 109,9 \\
\hline
\end{tabular}

Fonte: Carta Iedi, n.364, jun. 2009.

O excedente da demanda dos bens de alta e média-alta tecnologias sobre a oferta doméstica desses bens explica que o saldo entre exportações e importações desses produtos seja negativo. Somente os bens de baixa tecnologia têm um saldo positivo. ${ }^{19}$ Ora, são as exportações de média e alta tecnologias que permitem uma inserção sólida na economia mundial. De fato, as exportações de bens com conteúdo tecnológico elevado se caracterizam por uma elasticidade da demanda em relação à renda elevada no nível mundial, e são capazes de produzir efeitos favoráveis nos ramos industriais. A inserção na divisão internacional do trabalho é positiva e coloca os setores considerados ao abrigo da concorrência dos países com baixo salário. Os efeitos sobre o crescimento dessas exportações é elevado. Inversamente, as exportações de produtos de baixa tecnologia repousam especialmente sobre elasticidades da demanda relacionadas aos preços. Nesse caso, a inserção na divisão internacional do trabalho é negativa, já que as exportações não se apoiam no crescimento da renda em nível mundial mas na capacidade de baixar os preços. Os setores de baixa tecnologia sofrem com isso a concorrência dos países com mais baixo salário. Assim, a estrutura das exportações de produtos industriais no Brasil é potencialmente problemática.

A taxa de investimento dos últimos anos, embora em ligeiro crescimento (ver Quadro "Indicadores macroeconômicos"), permanece baixa, mais baixa que nos anos 1970, e bem mais baixa que nos países asiáticos. Segundo Pastore et al. (2010), a insuficiência de investimento, levando em conta o pequeno aumento da produtividade total dos fatores (supostamente medida pelo progresso técnico), impede o Brasil de atingir uma taxa de crescimento mais elevada. Essa insuficiência de investimento se deveria a uma poupança igualmente insuficiente,$^{20} \mathrm{e} \mathrm{o}$ país deveria assim apelar ainda mais à poupança externa do que já o faz. Atrair mais poupança externa a um custo no nível do balanço das contas correntes (pagamento de juros e dividendos em alta), segundo Pastore et al. (2010), 
aumenta seu saldo negativo, o que poderia conduzir à depreciação da moeda e frear a entrada de capitais. O modelo brasileiro estaria assim num círculo vicioso: quanto mais baixa e reduzida a poupança doméstica, tanto mais a poupança externa é necessária para elevar a taxa de investimento, ao mesmo tempo que os efeitos negativos sobre a balança das contas correntes e sobre a taxa de câmbio limitam a entrada dessa poupança. ${ }^{21} \mathrm{O}$ Estado deveria, portanto, consumir menos e limitar sua política de apoio à demanda a fim de romper esse círculo vicioso. Mas não foi esse o caminho escolhido pelo governo Lula nos últimos anos.

A fragilidade da taxa de investimento levanta duas interrogações importantes. 1) Quais são as razões que explicam a baixa taxa de investimento, quando as capacidades de produção são plenamente utilizadas e as taxas de rentabilidade são altas? Isso se deve ao atrativo do mercado financeiro? $\mathrm{Ou}$, dito de outro modo, a importância adquirida por esse mercado ${ }^{22}$ pesa negativamente sobre a taxa de investimento? 2) Não se pode limitar a análise a dados demasiadamente macroeconômicos, é preciso decompor a formação bruta de capital fixo em investimentos destinados à construção e em investimentos destinados aos equipamentos. A porcentagem da Formação Bruta de Capital Fixo (FBCF) destinada à construção diminuiu no período e passou de 42,8\% em 2003 para 35,3\% em 2008, para voltar a subir sensivelmente em 2009, ano da crise. Inversamente, a porcentagem destinada aos equipamentos e às máquinas aumentou. Essa evolução é positiva, mas a parte que corresponde à construção permanece elevada. Isso se deve à persistência de um comportamento especulativo? Baixa taxa de investimento, peso do mercado financeiro e comportamentos especulativos constituem obstáculos ao êxito da aposta feita no mercado interno para estimular o crescimento e diminuir a pobreza.

\section{Conclusão}

Seria equivocado atribuir os sucessos econômicos e sociais do presidente Lula à ação conduzida por seu predecessor, o presidente Fernando Henrique Cardoso, sob o argumento de que a política econômica seguida por Lula seria a realização daquela definida por Cardoso: liberalismo no domínio monetário (taxas de juros elevadas) e orçamentário (excedentes primários consideráveis). Mesmo que em parte isso possa ter fundamento, essa opinião peca por seu simplismo. Os regimes de crescimento não são os mesmos, as respostas às crises são diferentes. A crise financeira de 1998-1999 é em parte o resultado das fragilidades do modelo econômico posto em prática sob a direção de Cardoso. A "economia cassino" na qual se baseava a lógica desse regime de crescimento, ou seja, controle do balanço de pagamentos pelo jogo da taxa de juros para atrair capitais e financiar assim o serviço da dívida e o déficit da balança comercial, deixava a porta aberta "aos ventos contrários" da finança internacional e tinha como única saída lógica aplicar políticas de austeridade drásticas (grande elevação da taxa de juros, corte nos gastos públicos, especialmente sociais, desvalorizações) quando os capitais fugiam, a fim de recuperar uma credibilidade perdida junto aos mer- 
cados financeiros internacionais. Uma tal política precipitava a crise e sobretudo fazia recair seu custo sobre os mais vulneráveis, os pobres e as categorias mais modestas. Em sentido contrário, distanciando-se dos princípios do Consenso de Washington, ${ }^{23}$ a política seguida pelo presidente Lula foi buscar e acentuar a sustentação da demanda das unidades familiares por aumentos do salário mínimo e por transferências sociais mais consequentes do que no passado, pela elevação dos gastos públicos (precedida por uma leve reforma fiscal) e por maiores facilidades de crédito ao consumo e também à produção. Em relação a esses pontos, não há como deixar de constatar uma ruptura.

Tampouco, porém, se pode negar uma certa continuidade entre as políticas dos dois presidentes, sobretudo no primeiro mandato do presidente Lula: ampliação de uma bolsa escolar, criada por seu predecessor, para uma bolsa família; superávit primário do orçamento maior do que o exigido pelo FMI; apreciação da moeda nacional e manutenção de taxas de juros muito altas com o objetivo de reduzir a inflação, aplicando a "regra de Taylor" ${ }^{44}$ de inspiração monetarista. Mas a filosofia geral que subjaz a essas políticas liberais começa a ser diferente já no primeiro mandato de Lula: o governo se recusa a adotar a política de privatizações, preserva o estatuto público do seu grande banco, o $\mathrm{BN}$ DES (bem como do Banco do Brasil e da Caixa Econômica Federal), e escolhe sustentar a demanda mediante a elevação do salário mínimo e do crescimento dos gastos públicos. É essa política, como vimos, que está na origem de uma diminuição das desigualdades, de uma redução da pobreza e de uma aceleração do crescimento. Os dois mandatos do presidente Lula, portanto, não podem ser assimilados aos de FHC. Há semelhanças, mas também profundas diferenças.

O Brasil se encontra hoje numa encruzilhada. A forte retomada econômica e as políticas contracíclicas, decididas logo após a deflagração da crise internacional em 2008, poderiam servir de trampolim para a consolidação de um regime de crescimento iniciado no segundo mandato de Lula. Mas poderiam também reforçar a posição dos que desejam "fechar o parêntese da crise" e voltar ao regime de crescimento excludente dos anos 2000, por causa dos riscos de superaquecimento econômico, da sobrecarga dos custos de trabalho e do sistema de previdência social. Manter um equilíbrio entre duas filosofias econômicas opostas não será uma tarefa fácil para o futuro presidente da República do Brasil, ainda mais quando os conflitos de interesse entre grupos sociais são avivados pelo contexto da crise internacional. Manter as taxas de juros elevadas favorece o setor bancário, mas vai contra interesses dos industriais e de uma elevação do consumo estimulada pela expansão do crédito. Deixar que a moeda nacional se valorize favorece os importadores, mas desfavorece os exportadores de produtos manufaturados, ainda que surjam medidas protecionistas aqui e ali. Enfim, aumentar o salário mínimo recebe o assentimento das camadas da população mais modestas, estimula o crescimento, mas suscita reservas da parte de investidores submetidos a exigências de competitividade intensificadas pela crise e pela 
política de câmbio, faz pesar indiretamente as contas sociais do governo e pode conduzir a um aumento dos impostos. Num contexto de crise internacional, o conjunto desses interesses divergentes leva a romper o equilíbrio, de maneira mais nítida do que aconteceu durante o segundo mandato do presidente Lula, entre uma filosofia econômica monetarista e uma filosofia econômica de tipo keynesiano que privilegia a expansão do mercado interno. É o que explica que a dimensão política será determinante amanhã.

\section{Notas}

1 Quero agradecer aos meus amigos brasileiros Paulo Kliass e Cláudio Dedecca seus comentários.

2 Esse qualificativo é utilizado por Barbosa \& Pereira de Souza (2010). Ele não corresponde, porém, ao de "novo desenvolvimentismo" utilizado por Bresser-Pereira (2009).

3 O superávit primário é a diferença entre as receitas orçamentárias e os gastos públicos, excetuados os pagamentos dos juros da dívida pública, externa e interna.

4 Todos os dados estatísticos provêm do Banco Central do Brasil ou do IBGE.

$5 \mathrm{O}$ saldo do balanço em conta corrente é composto do saldo da balança comercial, dos gastos líquidos de turismo, dos seguros e custos de transporte e, sobretudo, do pagamento de juros da dívida externa e dos dividendos e lucros líquidos repatriados. Os gastos líquidos de turismo tendem a aumentar com a apreciação da moeda, os dividendos e lucros repatriados aumentam, estruturalmente, de forma paralela à internacionalização crescente do capital no Brasil e, conjunturalmente, segundo as necessidades de financiamento das empresas-mãe e das antecipações dos investidores. O serviço da dívida externa tende a baixar com a redução das taxas de juro internacionais (entre as quais a baixa do spread, ou seja, da prime de risco) e a contração da reserva líquida da dívida externa.

6 A contribuição ao crescimento do consumo e do investimento foi negativa em 2003, e a taxa de crescimento positiva se explica por um ambiente internacional favorável que permitiu um vigoroso impulso das exportações.

7 Em 1998, o pagamento dos juros da dívida externa, a remessa ao estrangeiro dos dividendos e os lucros repatriados correspondiam a $2,2 \%$ do PIB. Em porcentagem do valor das exportações, os dividendos e lucros repatriados baixam de 35,6\% em 1998 para $18,2 \%$ em 2007. Essa redução é ainda mais pronunciada quando relacionamos esses pagamentos às reservas: $40,8 \%$ e 16,2\% nas mesmas datas. Em valor absoluto, porém, os dividendos tendem a aumentar com o crescimento dos investimentos estrangeiros diretos e ultrapassam o pagamento dos juros da dívida pública externa. Em 2003, os dividendos e lucros repatriados se elevavam a 5,6 bilhões de dólares e, em 2005, a 12,7 bilhões de dólares; nas mesmas datas, os juros da dívida se situavam em 13 e 13,5 bilhões, respectivamente. Em 2008, os lucros repatriados aumentam muito, em consequência da crise e da busca de liquidez, e o conjunto dividendos/lucros repatriados se eleva a 33,9 bilhões de dólares, contra 7,2 bilhões para o pagamento dos juros.

8 Lembramos que esses números correspondem ao crescimento do "estoque" dos investimentos em carteira e não aos fluxos brutos. Sendo números de fim de ano, eles não traduzem os movimentos intra-anuais, que podem ser de grande amplitude. 
9 A bibliografia sobre essas questões é muito extensa e as instituições internacionais têm há muito analisado os canais de transmissão para explicar o efeito de contágio. Para uma análise que não se limita apenas aos canais de transmissão, ver Salama (2009) e nossas contribuições ao livro coordenado por Hugon \& Salama (em especial Salama, 2010a, 2010b).

10 O número de pessoas com mais de um milhão de dólares de ativos financeiros aumentou mais de $10 \%$ entre 2005 e 2006, e 19\% no ano seguinte, segundo Capgemini e Meryl Lynch.

11 Embora ainda modestos comparados aos dos países europeus, eles aumentaram sensivelmente. Segundo os trabalhos de Afonso \& Dain (2009), ultrapassaram 24,4\% do PIB em 2007.

12 Cf. OCDE (2006).

$13 \mathrm{O}$ coeficiente de Gini mede as desigualdades. Seu valor é compreendido entre 0 e 1 , em realidade entre 0,3 e 0,6. Quanto mais o valor se aproxima de 1 , tanto mais o país é considerado desigual. Na América Latina, ele se situa entre 0,45 e 0,6, conforme os países.

14 Segundo um comunicado da presidência do Instituto de Pesquisa Econômica Aplicada (Ipea), n.22, 2009, a carga bruta do imposto em 2004 e em 2008 era de 48,8\% e $53,9 \%$, respectivamente, para os que ganhavam menos de dois salários mínimos, e de $26,3 \%$ e $29 \%$ para os que ganhavam mais de 30 salários mínimos. Calculada em dias de trabalho, em 2008, essa carga bruta representava 197 jornadas para os primeiros e 106 para os segundos.

15 Analisamos a relação entre regime de crescimento e natureza dos empregos criados no Brasil em Salama (2008).

16 Ver Cepal (2009), Lopez-Calva \& Lustig (2002) e Dedecca (2010). Duas observações: os rendimentos dos $0,01 \%, 0,1 \%$ ou mesmo $1 \%$ cresceram bem mais depressa, como no conjunto dos países ocidentais; os rendimentos do capital (juros, dividendos etc.) são muito mal registrados.

$17 \mathrm{Em}^{\circ}$ de abril de 2003, pouco depois da chegada de Lula ao poder, o salário mínimo era de 250 reais; em $1^{\circ}$ de janeiro de 2010 , passou para 510 reais, ou seja, mais ou menos 260 dólares (ver sua evolução no Quadro "Indicadores macroeconômicos"). É bom lembrar, porém, que uma parcela importante dos trabalhadores no Brasil tem rendimentos amplamente inferiores ao salário mínimo. A linha de pobreza está em torno de 200 reais por mês, muito aquém do salário mínimo, e a porcentagem de pobres é de cerca de um quarto da população.

18 Sobre os efeitos do conjunto das transferências sociais sobre o nível de pobreza, ver Rocha (2010).

19 Para uma comparação com outras economias emergentes, ver Mulder (2009).

20 Poupança pública, em razão da multiplicação das isenções fiscais e do aumento dos gastos do Estado com a crise, e poupança privada, por causa da propensão a consumir muito elevada.

21 Os autores parecem fazer uma confusão entre balanço das contas correntes e conta de capital. As entradas líquidas de capitais podem ser superiores aos efeitos induzidos (pagamentos de dividendos e juros) dessas entradas sobre o balanço das contas correntes. Acrescentemos ainda que o aumento da taxa de investimentos, inclusive graças ao 
recurso da poupança externa, pode levar a um aumento das exportações e à melhora do saldo da balança comercial se esses investimentos forem dirigidos para a produção de bens exportados, como aconteceu na Coreia nos anos 1970.

22 Para uma abordagem crítica recente a partir de um ponto de vista keynesiano, que insiste na dimensão da regulação financeira, ver Cardim de Carvalho \& Pires de Souza (2009).

23 O Consenso de Washington é um conjunto de medidas que preconizam a liberalização externa (redução das taxas de importação, subvenções à exportação, liberdade de circulação de capitais, taxas de câmbio competitivas) e interna (privatização, desregulação do sistema bancário e aumento das taxas de juros com abandono das taxas preferenciais, reforma tributária e ampliação da base fiscal, disciplina fiscal), e o respeito aos direitos de propriedade. Essas medidas são explicitamente os "dez mandamentos" da boa gestão...

24 A regra de Taylor busca reduzir a taxa de inflação. Uma taxa de inflação é fixada como meta, levando em conta a evolução limite da produção (crescimento potencial). A política monetária (alta das taxas de juros) é o instrumento privilegiado para atingir a meta de inflação, acompanhada de uma política cambial (apreciação da moeda) e de uma política orçamentária restritiva.

\section{Referências}

AFONSO, J. R.; DAIN, S. Dos decadas de la descentralizacion del gasto social en Americal Latina: una evaluacion preliminar. Working Paper, Cepal, 2009. Disponível em: <http://www.eclac.org>.

BARBOSA, N.; PEREIRA DE SOUZA, I. A. A inflexão do governo Lula: política econômica, crescimento e distribuição de renda. In: SADER, E.; GARCIA, M. A. Brasil, entre o passado e o futuro. São Paulo: Boitempo, 2010.

BRESSER-PEREIRA, L. C. Mondialisation et compétition, pourquoi quelques pays emergentes réussissent alors que d'autres non. Paris: La Découverte, 2009.

CARDIM DE CARVALHO, F.; PIRES DE SOUZA, F. E. Financial regulation and macro economic stability in Brazil in the aftermath of the Russiam crisis. Working Paper, UFRJ, 2009.

CEPAL. Balance preliminar de las economias de America latina y el Caribe, 2009.

DEDECCA, C. S. As desigualdades na sociedade brasileira. Working Paper, 2010. (Mimeogr.).

GONI, E. et al. Fiscal Redistribution and Income Inequality in Latin America. Policy Research Working Paper, n.4487, 2008.

LOPEZ-CALVA, F.; LUSTIG, N. The recent decline of Inequality in lation America: Argentina, Brazil, Mexico and Peru. Working Paper, n.140, Ecineq, 2002.

MULDER, N. Weak links between export trade and economic growth in Latin America ant the Caribean. Working Paper, n.91, 2009. Série Comércio Internacional, Cepal.

OCDE. Perspectives économiques de l'Amérique Latine, 2006. 
PASTORE A. C. et al. Limites ao crescimento econômico. Working Paper, 2010. (Mimeogr.).

PAULA, L. F. de. Twenty years of economic policy under neoliberal era in Brazil. 2010. Disponível em: <http://www.joserobertoafonso.ecn.br>.

ROCHA S. Transferências de renda e pobreza no Brasil. Tiers Monde, 2010. (No prelo).

SALAMA, P. Pauvreté, le bout du tunnel? Problèmes d'Amérique Latine, n.66/67, 2008. n.197, 2009

Argentine, Brésil, Méxique face à la crise internationale. Revue Tiers Monde,

Une crise financière structurelle. In: HUGON, P.; SALAMA, P. (Coord.) Les Suds dans la crise. Paris: Armand Colin, 2010a.

Forces et faiblesses de l'Argetine, du Brésil et du Méxique. In: HUGON, P.; SALAMA, P. (Coord.) Les Suds dans la crise. Paris: Armand Colin, 2010 b.

RESUMO - Aparentemente duas filosofias econômicas opostas caracterizam a política econômica seguida pelos governos sucessivos sob a presidência de Lula. Uma, monetarista, busca frear a alta dos preços: taxas de juros reais muito elevadas, superávits primários consideráveis, apreciação da moeda nacional. Ela explica ao mesmo tempo as dificuldades de fazer crescer a taxa de investimento, aumentar o valor agregado dos bens produzidos e favorecer a produção de bens de alto conteúdo tecnológico. A outra, keynesiana, busca diminuir as desigualdades, aumentar o salário mínimo e assegurar uma cobertura social mais ampla. Ela explica a taxa de crescimento elevada e o novo dinamismo do mercado interno. Com a crise internacional, a segunda filosofia influencia mais a política econômica do que no passado e oferece a oportunidade de ingresso numa nova era, contanto que seja removido o obstáculo de um sistema fiscal regressivo e contanto que se crie, no futuro, uma política industrial mais ativa que diminua os riscos de primarização que ameaçam o Brasil.

PALAVRAS-CHAVE: Escolha tecnológica, Distribuição de renda, Rendimentos do trabalho, Exportação, Antipobreza.

ABSTRACT - It appears that successive governments under Lula's presidency followed two opposite economic philosophies. The first one, the monetarist philosophy, aims to curb increases in prices: very high real interest rates, important primary budget surpluses, appreciation of the national currency. This explains the difficulties in raising investment rates, in raising the added value of products and in promoting the development of production of high technology content products. The secon one, Keynesian, aims to reduce inequalities, to raise minimum real wages and to ensure wider social security cover. It explains high growth rates and domestic market renewed dynamics. Because of the international crisis, this second philosophy influences economic policies more heavi- 
ly than in the past, and offers an opportunity to enter a new era, providing however that the obstacle of a regressive tax system is removed and providing the implementation for the future of a new, more active, industrial policy lowering the risks of primarisation currently threatening Brazil.

KErWORDS: Technological choice, Income distribution, Labor income, Export led, Anti poverty.

Pierre Salama é doutor em Economia pela Universidade Paris-Sorbonne, professor da Universidade Paris XIII, membro do Conselho Científico e do Conselho de Relações Internacionais da mesma universidade. É autor de vários livros, entre eles, no Brasil: Pobreza e exploração do trabalho na América Latina (Boitempo, 2002).

@ - pierresalama@gmail.com

Traduzido por Paulo Neves. O original em francês - "Brésil, bilan économique, succes et limites" - encontra-se à disposição do leitor no IEA-USP para eventual consulta.

Recebido em 7.6.2010 e aceito em 17.8.2010. 